\title{
Accentuated Factors of Handheld Computing
}

\author{
Andersson, Bo; Henningsson, Stefan
}

Document Version

Final published version

Publication date:

2011

\section{License \\ CC BY-NC-ND}

Citation for published version (APA):

Andersson, B., \& Henningsson, S. (2011). Accentuated Factors of Handheld Computing. Paper presented at International Conference on Information Systems Development (ISD 2011), Edinburgh, Skotland, United Kingdom.

Link to publication in CBS Research Portal

\section{General rights}

Copyright and moral rights for the publications made accessible in the public portal are retained by the authors and/or other copyright owners and it is a condition of accessing publications that users recognise and abide by the legal requirements associated with these rights.

\section{Take down policy}

If you believe that this document breaches copyright please contact us (research.lib@cbs.dk) providing details, and we will remove access to the work immediately and investigate your claim. 


\title{
Accentuated Factors of Handheld Computing
}

\author{
Bo Andersson and Stefan Henningsson
}

Department of Informatics, Lund School of Economics and Management, Lund University, Ole Römers väg 6, SE-22363 Lund, Sweden. Email: bo.andersson@ics.lu.se - corresponding author -

Center for Applied ICT, Copenhagen Business School, Howitzvej 60, 2000 Fredriksberg, Denmark. Email: sh.caict@cbs.dk

\begin{abstract}
The recent years of rapid development of mobile technologies creates opportunities for new user-groups in the mobile workforce to take advantage of information systems (IS). However, to apprehend and harness these opportunities for mobile IS it is crucial to fully understand the user group and the mobile technology. In this paper we deductively, from previous research on aspects on mobility, synthesize a tentative analytical framework capturing factors accentuated in mobile IS design. We evaluate the framework based on criteria of completeness, distinctiveness, and simplicity. Eventually, these two steps develop the framework towards a theoretical contribution as theory for describing handheld computing from a designer's perspective. Thirteen semi-structured interviews were made and the tentative framework was elaborated and confirmed.
\end{abstract}

\section{Introduction}

The recent years of rapid development of mobile technologies creates opportunities for new user-groups in the mobile workforce to take advantage of Information Systems (IS) based on mobile technologies - mobile IS. However, to apprehend and harness these opportunities it is crucial to fully understand the user group and the mobile technology [1].

There are evidence in the form of IS failure supporting the opinion that we still have lessons to learn on how to design and develop mobile IS for the mobile workforce. For example, a large corporate group in northern Europe within the heavy industry and haulage sector implemented a service order system for their 280 service technicians in Sweden, where the end user platform was handheld computers. Savings due to shorter lead- time from ordered service to sent invoice was one of the main reasons for developing and implementing the system. The desired benefits were achieved when the time from order to invoice was cut from three weeks to three days. The service technicians, however, deemed the system a failure owing to increased administration on their part from 20 to 90 minutes per day and lack of support for the service technicians' vital information needs. Postimplementation evaluation showed that the production loss caused by the techni- 
cians spending more than one hour less per day actually performing service could have been avoided if the system had been adapted to how the technician performed service order administration in the field [2].

Similar stories in the business press and academic literature indicates that the example above is not an isolated anecdote but a typical example of how mobile IS projects do not harness the potential due to failure in understanding the use situation and the nature of the handheld computing device [3-7]. This is the motivation behind this paper and its focal point in the concept of mobility and what characterizes mobile IS from a designer's perspective.

\section{Objectives}

The paper is based on the proposition that mobile IS has distinctive characteristics compared to the more traditional IS in in the shape of stationary IS [8,9]. Our purpose is to develop and evaluate a framework for capturing aspects of handheld computing to be of importance during the analysis and design phases of mobile IS development. The intended use of this framework is in the design phase of the construction of a mobile information system for the mobile workforce. The intended user is a person working with the early design and requirement specifications. Consequently, pure technological aspects as antennas, roaming, and handover are not dealt with. The focus are neither differences in the IS content, i.e. potential distinction of what kind of IS applications are being used in traditional and mobile IS nor by which purpose. We are interested in entities that may be managed, or dealt with, in a IS design and development situation.

A specification of the core topic is warranted here. We are principally discussing handheld computing although in the majority of research the term mobile computing have more or less been equated with handheld computing. In this paper the framework is only applicable on handheld devices where the small form factor [8] is applicable. Another important aspect is that the context for this research is the mobile workforce; an effect of this is the treatment of mandatory versus voluntary use. The assumption is that in the workforce setting the use most often are mandatory and that this will influence use and design.

In a first step this paper deductively synthesise a tentative analytical framework for capturing the accentuated factor of mobile IS, based on previous research on aspects on mobility and approaches to analyze mobile IS use and technology in IS design. 'Accentuated' in this paper refers to factors that are new; factors that have gained importance; or factors where the meaning have changed.

In a second step we use interviews with IS designers and developers to evaluate the framework's qualities. Thereafter we evaluate the framework based on criteria of completeness, distinctiveness, and simplicity (see section 4). 


\section{Related Literature}

Much research has been done on mobile IS and mobility per se [10-12] but the conceptualization of the term and what implication mobility has for IS design is still limited. Several frameworks have been developed in order to describe or explain aspects of mobility and IS use in a mobile context. Zheng \& Yuan's [1] framework with the entities' mobile workers, mobile context, mobile tasks and mobile technologies is developed to describe differences between stationary and mobile context. Kakhira \& Sörensen's [13] discusses mobility and includes temporal, spatial and contextual mobility into mobility as a phenomena. Focusing on design Tarasewich suggests context to be divided into three categories: activities, environment and participants [14]. All of these frameworks are important contributions to the field of mobile IS, but they are not specifically developed and focused on the design of mobile IS and furthermore, they are not evaluated. They are more or less a loosely coupled set of factors assembled by the author. A comprehensive and evaluated analytical framework informing system designers is still missing.

One of the few attempts to illustrate factors related to mobile IS design and development with an intended audience of designers, is the additional dimensions of mobility by B'Far [15]. As a consequence of this, in the construction of the basic framework we departure from B'Fars [15] framework of additional dimensions of mobility. Why we only depart from these dimensions, and not solely uses them, are because these seven dimension are not exhaustive, this will be discussed in the following section. B'Far identifies seven different dimensions as a result of mobility. Active transactions, Limited Device Capabilities, Wireless Connectivity, Location Awareness, Limited Power Supply, Large Variety of Platforms and Multimodal and Variant User Interfaces (figure 3.1).

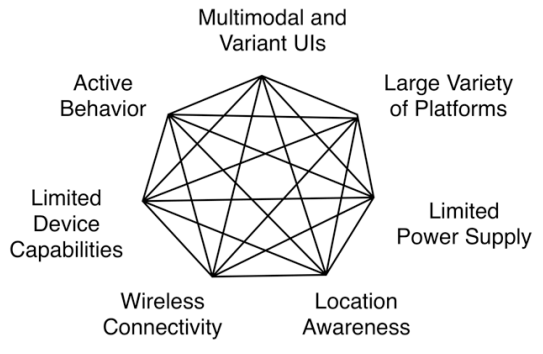

Fig. 3.1 The additional dimensions of mobile computing according to B'Far [20]. 


\subsection{Some issues with B'Far's framework}

However there are some issues with the consistency in B'Far's [15] framework; some of the different dimensions are of different magnitude or quantity. Wireless Connectivity, Multimodal and Variant UIs and Location Awareness is healthy but Limited Device Capabilities, Limited Power Supply, Large Variety of Platforms are values on some scale and Active Behaviour is a desired interaction pattern. A more detailed description and motivation for altering dimensions are presented below. Another issue is the edges (lines) between the dimensions, B'Far [15] do not explain their contribution to the dimensions. Is it that every dimension affects all other dimensions? If so, do they affect in the same magnitude in every case?

Another crucial aspect is our rejection of the concept "dimension"; using dimension imply equivalent units of measure, that not are easily constructed. We argue that "factor" is more descriptive, that is; "a factor is one of the things that affects an event, decision or situation" [16, p. 595]. In this context, the factors in the framework can affect the outcome of a built system depending on how it is managed in the design and development of the system. And factor will be used henceforth.

Active behaviour: Active behaviour illustrates an interaction pattern a mobile application is supposed to have accordingly to B'Far. [15]. The mobile user is anticipated to benefit on short interaction sequences, short time periods of use, reluctance against long boot sequences and active behaviour is patterns to manage this. The main reason is that the mobile workforce is often occupied with other task than working with their computer, a view supported by Marcus and Chen [17], Pascoe et al. [18], Kristoffersen and Ljungberg [19]. However, active behaviour is one interaction pattern among others and the factor is relabelled as Interaction Patterns. That is, the mobile user may, or may not, have tasks that will benefit on the interaction pattern of active behaviour.

Multimodal and variant UIs: This factor is complex and regards the small form factor with small screen and limited keyboard but also the increased interaction possibilities as using voice, sound, motion as input and output devices and the variation of different settings as differences between different keyboards or different screen resolution. Keyboard may be missing or offering a keyboard with limited set of keys compared to an ordinary keyboard $[15,20]$. This factor is relabelled to Small From Factor: Interface, the main reason to relabeling it that small form factor is a well known concept in mobile and handheld computing.

Large variety of platforms: The mobile industry is characterized with a large and heterogeneous set of actors and stakeholder. This creates a complex ecosystem with competing technologies and standards that in turn affect designers trying to design systems functional on different platforms. In respect of this set of actors and the in the case of mobile applications the platform variation is large, meaning; large variations of operating systems among the handhelds and large variation of hardware configurations $[21,15]$. These aspects remains in this factor, however re- 
named as Platform Variation removing the adjective large because it implies a value. There may be cases where the variation is small.

Limited power supply and limited device capabilities: Both of these factors relates to hardware capabilities. Limited power supply is a factor that is highly relevant for mobile devices, since in practice they require to be battery powered and independent of the fixed power networks. Limited device capabilities regard chiefly the effects of miniaturization on hardware. Effects are reduced processing capability, limitations in storage et cetera [15]. However these to factors are strongly related to each other that they are placed in the same factor and the value (limited) is deleted, renaming it to Small Form Factor: Hardware.

Location awareness: Handheld devices are mobile and therefore able to appear in different places and they can by different means use information of its physical location. This location awareness can be achieved by GPS, triangulation, accessing nodes or other techniques. [15]. There has been a considerable amount of work on location-based services mainly of conceptual type or for marketing [22] but lesser work has been done on supporting the mobile workforce with applications using location awareness. This factor remains unchanged in Location Awareness.

Wireless connectivity: The factor Wireless Connectivity illustrates the unpredictability of Quality Of Service both in transmission rate and connectivity. With wireless networks disconnection is an factor to manage. Temporary disturbances as sun flares, road tunnels, interference and skip zone affects the transmission. $[15,23]$. These factors, possible variation in transmission rate and possible variation in connectivity remains in the unaltered factor Wireless connectivity.

\subsection{Extending B'Far}

When performing a literature review, some other factors surface. By adding these factors we are gaining a more comprehensive framework on accentuated factors.

Field-Use Condition: For the mobile workforce most work is obvious done at the field, rendering a use situation often labelled field use conditions. Field-use conditions could incorporate social settings, supporting technologies, supportive colleagues et cetera. However we argue that field use condition regards the physical surroundings as quiet or noisy environments, sunlight, darkness, heat or low temperature all influencing the field-use in their on ways. The lack of a predefined workplace is also a part of this factor, mobile workers need to adapt to different and diversified workplaces $[24,25,12]$. This factor is labelled Field-use Conditions.

Anywhere: Anywhere is almost a trademark of handheld computing and depictures freedom of place. However there is some ambiguity in the interpretation of anywhere, do anywhere illustrate the mobility of the user; or the mobility of an application; or the mobility of a document [26,12,27]. 
In this paper anywhere illustrates the mobility of the user, however, in a work situation the interpretation of freedom of place can be questioned. We argue that for the mobile workforce and mandatory use the user most likely are not allowed to choose the place, on the contrary, the place may be specific. A "just on place" requirement is more applicable, for example, it may be important that a doctor is at a specific place to do something. For clarity of the possible restrictions on anywhere the alternative label Place Critical is put forth and will be used in the forthcoming framework.

Anytime: Anytime are closely related to anywhere and usually describes that the user can access certain information, a service or an application when the user wants, a freedom in time $[15,26,12]$. The same ambiguity as for anywhere surface; to contrast the conception of freedom in time, when users actually do need information it is often relatively time-critical information such as the repair status on a machine or a some purchasing status just before a client meeting. For the same reasons as for anywhere, "just in time" is a more accurate term to illustrate the mobile workforce and mandatory use relation to freedom in time. For clarity of the possible restrictions on anytime the alternative label Time Critical is put forth and will be used in the forthcoming framework.

Security Issues: In wireless communication security issues is present due to the risk of interception. These may be the different types of threats as masking, listening, browsing, distortion [28,29]. Another security issue is the small form factor and its omnipresence. The handheld device's small size opens up to the factor to be carried along in a greater extent than, for example, a laptop computer. This frequent exposure increases that the risk of it being stolen or lost (greater exposure in foreign environments) than for example a desktop computer $[30,28]$. These two security issues, wireless transmission threats and the increased risk of device being lost are merged in the factor Security Issues.

Supporting Technologies: Compared to the office worker, the mobile workforce accessibility to supporting technologies is often limited. Important documents may not be easily accessed and displayed through a handheld device. File management, servers, fax machines, written manuals, written ledgers or other support systems may not be available in the same extent as in a office environment $[24,1]$. This factor is labelled Supporting Technologies

Support Situation: The fact that a considerable part of the mobile workforce is working by themselves on the field renders a lack of colleagues to interact with in an informal fashion. The coffee room interaction [31] are missing and furthermore, offering IT/IS support can be more problematic due to the sheer distance [32]. This factor is labelled Support Situation

Information System Dependencies: IS dependencies regards the mobile workforce high reliance on their information system. If an implemented application is the only application the user may access, and this application is crucial for the user to conduct the work, the reliance on this application is high. If the application malfunction, or that the implemented workflow do not match the actual/real workflow these problems will have extensive negative impact on perceived usefulness and 
productivity $[2,33]$. The options to "bypass" problems with PostIt-notes or other IS-application are often lesser. This factor is labelled Information System Dependencies.

\subsection{A Tentative Framework}

Departing from B'Fars [15] seven dimensions, and by a literature review extending it, a framework of 13 aspects was built. Some of the labels from B'Fars framework were altered to reduce logical inconsistencies as being of different magnitude or quantity.

The tentative framework based on previous research on factors concerning handheld computing is: Field-use conditions; Information system dependency; Interaction Patterns; Location awareness; Place critical; Platform variation; Security Issues; Small form factor-Hardware; Small Form Factor-Interface; Support Situation; Supporting Technologies; Time Critical and Varying connectivity.

We deliberately choose not to illustrate the factors in a graphical notion as B'Far, just because we do not want to confuse the reader as we were imposing relations between factors.

\section{Method}

The framework put forth in this paper is an example of theory for analysing and describing [34]. The framework in form of a collection of individual factors can be considered as a theory for describing the components of handheld computing, that is "The theory does not extend beyond analysis and description. No causal relationships among phenomena are specified and no predictions are made" [34, $p$ 620]. The evaluation criteria for theory for analysing suggested by Gregor is applied. We conclude that the usefulness of this type of theory may be refined to be evaluated by its completeness, distinctiveness, and simplicity. Completeness means that important categories or elements should not be omitted from the classification system, that is, the framework should be able to capture all important resources. Distinctiveness means that boundaries between categories and characteristics that define each category are clear. The empirical phenomena encountered should be possible to categorize according to these criteria without too much difficulty. Simplicity refers to that which by making a model or framework too elaborated or comprehensive, it makes it hard to work with and in the end makes it useless for its purpose [34].

The empirical data required to assess the frameworks usability was gathered by semi-structured face-to-face interviews. Thirteen informants with experience of design and development of handheld applications were interviewed (see table 1). 
8 Bo Andersson and Stefan Henningsson

\begin{tabular}{lll} 
Table 1. Informant profiles & & \\
\hline Job title & Employer & $\begin{array}{l}\text { Year of experience of } \\
\text { mobile development }\end{array}$ \\
\hline Senior developer & Cybercom & 8 \\
Software engineer & Mashmobile & 6 \\
CEO & Qubulus & 11 \\
Development Consultant & Stratal & 7 \\
Program owner & Cybercom & 11 \\
Senior developer & Mobimation & 14 \\
Software engineer & Yahm & 4 \\
Software engineer & QlikTech & 5 \\
Software developer & Databolaget & 6 \\
Program manager & Logica & 5 \\
CTO & WIP & 12 \\
Program Manager & Sigma & 3 \\
Program Manager & Sogeti & 12 \\
\hline
\end{tabular}

The interviews had an average duration of 1 hour and 30 minutes. All interviews revolved around what the informant considered being significant in design of mobile information systems, differences between stationary/desktop design, about the importance of the factors derived from literature and the applicability of a framework as such. All interviews were recoded and transcribed. After each interview transcriptions were coded into groups related to factors and analysed chronologically in order to identify eventual saturation. The QDA software HyperResearch was used during analysis. Saturation here refers to that no additional, unknown comments or suggestions regarding the three evaluation criteria came up during the interview and saturation was reached after five interviews. Due to saturation, after nine interviews the interview guide were modified, aiming to also find dependencies between factors, however the interviews still revolved the factors and were possible to analyse in line with the preceding nine interviews.

\section{Framework Evaluation}

The empirical evaluation of the framework was in large extent in favour of the tentative framework, however regarding completeness suggestions on adding one factor was put forth (see following section). Concerning distinctiveness, suggestion on the separation of aspects in one factor was also put forth (see following section). Concerning simplicity, all informants allege they understood the factors (see table 2).

High Velocity Environment, was suggested as an additional factor. It illustrates the fast changing environment with competing vendors, manufacturers and content 
providers and it was argued that this factor is more fierce and withstanding than within stationary computing. High Velocity Environment exists in stationary computing but the importance of this factor is greater in handheld computing. The lifecycle of an application is shortened on a handheld device due to shorter expected lifetime of the device, more frequent changes in operating systems versions (with low degree of backward compatibility) and faster changes in carriers platforms etcetera. However, the label High Velocity Environment on this factor imply a value and to be consistent it is relabelled to Industry Dynamics.

Another factor created from the evaluation was Multimodal Interfaces. This aspect already exits in the framework in Small Form Factor: Interface, however, it was argued that a separation of concerns was necessary. Small Form Factor: Interface should concern the reduction on interface due to the small form factor. Multimodal interface however, is not a consequence of small form factor; it is a set of new I/O possibilities as motion control or LDR sensors and therefore should be distinguished by an own factor: Multimodal Interface.

Table 2. The informants evaluation on factors

\begin{tabular}{llll}
\hline Informant & Completeness & Distinctiveness & Simplicity \\
\hline A & Add High velocity & Agree & Agree \\
& env. & & \\
B & Agree & Agree & Agree \\
C & Agree & Agree & Agree \\
D & Agree & Agree & Agree \\
E & Agree & Division of SFF-Interface and - Agree \\
& & Multimodal interface & \\
F & Agree & Agree & Agree \\
G & Agree & Agree & Agree \\
H & Add High velocity & Division of SFF-Interface and - Agree \\
& env. & Multimodal interface & \\
I & Agree & Division of SFF-Interface and - Agree \\
& & Multimodal interface & \\
J & Agree & Agree & Agree \\
K & Agree & Agree & Agree \\
L & Agree & Agree & Agree \\
M & Agree & Agree & Agree
\end{tabular}

To summon the evaluation of the accentuated factor framework, the informants supported the tentative framework although with the extension of two factors. Some comments on the framework applicability were that they regarded the framework as highly useful for senior designers with project management assignments and for persons responsible for procurement of IS/IT solutions and likes. Both in design/development and in benchmarking of existing competing systems in a procurement process. As two informant puts it: 
This framework would be useful for anyone procuring a mobile $I S$, assisting that person to evaluate if all, for that specific case, important factors are recognised (Senior Developer, Cybercom).

Useful to use this framework and to specify the important factors in design, and also to evaluate an existing system and see if it matches the needed requirements (Senior developer, Mobimation)

The final framework of accentuated factors for mobile information systems are: Field-use conditions; Industry Dynamics; Information system dependency; Interaction Patterns; Location awareness; Multimodal interfaces; Place critical; Platform variation; Security Issues; Small form factor Hardware; Small Form Factor -Interface; Support Situation; Supporting Technologies; Time Critical; Varying connectivity.

\section{Conclusions}

With the ambition of improving mobile IS design and development, we have in this paper put forth a framework for describing accentuated factors in IS design for handheld computing from a designers perspective.

Theoretically, we add to the existing knowledge base on mobile IS design in two regards. First, we apply a holistic approach on the accentuated factors by synthesizing previous literature into a comprehensive framework, second, that we evaluated and expanded it based on evaluations by experienced designers.

Practically, the proposed framework was evaluated based on the criteria that it should help mobile IS designers to better apprehend the properties of handheld computing. It can be used as an analytical tool in the design process to ensure that the accentuated factors are appropriately recognized, or as a tool for analysing competing solutions in the procurement process.

In this article we commence a theorization process aimed at analyse and describe accentuated factors of mobile IS design, with the final goal of providing mobile IS designers with tools to dealing with the particular problems with mobile IS design.

We foresee that the next steps in a cumulative process towards this ambition would be furthering of the empirical basis for drawing conclusions of the interdependencies between factors, that is, how do different factors affect each others and more in-depth analysis of the importance of the factors - finding critical factors. For example, explanatory theory to design artefacts fitting the work context of mobile IS designers will be needed. 


\section{References}

1. Zheng W, Yuan Y (2007) Identifying the differences between stationary office support and mobile work support: a conceptual framework. Int J Mob Commun 5 (1):107-123

2. Andersson B (2008) About Appropriation of Mobile Applications - The Applicability of Structural Features and Spirit. Paper presented at the Proceedings of the European Conference on Information Systems (ECIS), Galway,

3. Allen D, Wilson TD (2005) Action, interaction and the role of ambiguity in the introduction of mobile information systems in a UK police force. Mobile Information Systems-Bk 158:15-36

4. Blechar J, Constantiou I, Damsgaard J (2005) The role of marketing in the adoption of new mobile services: Is it worth the investment? ICMB 2005: International Conference on Mobile Business:370-376

5. Luff P, Heath C (1998) Mobility in collaboration. Paper presented at the Proceedings of the 1998 ACM conference on Computer supported cooperative work, Seattle, Washington, United States,

6. Norman A, Allen D (2005) Deployment and use of mobile information systems. Mobile Information Systems II 191:63-78

7. Steinert M, Teufel S (2005) The European mobile data service dilemma - An empirical analysis on the barriers of implementing mobile data services. Mobile Information Systems II 191:63-78

8. Fällman D (2003) In Romance with the Materials of Mobile Interaction : A Phenomenological Approach to the Design of Mobile Information Technology. Umea University, Umeå

9. Lyytinen K, Yoo Y (2002) Research commentary: The next wave of Nomadic computing. Information Systems Research 13 (4):377-388

10. Dahlberg P (2003) Local mobility. Diss Göteborg Univ, 2003, Department of Informatics, Univ.,, Göteborg

11. Kristoffersen, Ljungberg Representing Modalities in Mobile Computing - A Model of IT use in Mobile Settings. In: Proceedings of Interactive Applications of Mobile Computing, Rostock, 1998.

12. Perry M, O'hara K, Sellen A, Brown B, Harper R (2001) Dealing with mobility: understanding access anytime, anywhere. ACM Trans Comput-Hum Interact 8 (4):323-347. doi:http://doi.acm.org/10.1145/504704.504707

13. Kakihara M, Sørensen C (2002) Mobility: An Extended Perspective. Paper presented at the 35th Annual Hawaii International Conference on System Sciences (HICSS'02),

14. Tarasewich P (2003) Designing Mobile Commerce Applications. Association for Computing Machinery Communications of the ACM 46 (12):57-60

15. B'Far R (2005) Mobile computing principles : designing and developing mobile applications with UML and XML. Cambridge University Press, New York 16. Sinclair J (1995) Collins COBUILD English dictionary. Collins Reference,

17. Marcus A, Chen E (2002) Designing the PDA of the future Interactions 9 (1):35-44 
18. Pascoe J, Ryan N, Morse D (2000) Using while moving: HCI issues in fieldwork environments. ACM Trans Comput-Hum Interact 7 (3):417-437

19. Kristoffersen S, Ljungberg F (1999) "Making place" to make IT work: empirical explorations of $\mathrm{HCI}$ for mobile CSCW. Paper presented at the Proceedings of the international ACM SIGGROUP conference on Supporting group work, Phoenix, Arizona, United States,

20. Fallman D, Lund A, Wiberg M Scrollpad: Tangible scrolling with mobile devices. In, 2004. p 6

21. Andersson B, Hedman J (2007) Developing m-Services: Lessons Learned from the Developers' Perspective. Communications of the Association for Information Systems 20 (1)

22. Tilson D, Lyytinen K, Baxter R A framework for selecting a location based service (LBS) strategy and service portfolio. In, 2004. pp 5-8

23. Dunlop M, Brewster S (2002) The challenge of mobile devices for human computer interaction. Personal and ubiquitous computing 6 (4):235-236

24. Brown B, Kenton O'Hara B (2003) Place as a practical concern of mobile workers. Environ Planning A 35 (9):1565-1588

25. Marcus A, Gasperini J (2006) Almost dead on arrival :a case study of nonuser-centered design for a police emergency-response system. Interactions 13 (5): $12-18$

26. Makimoto T, Manners D (1997) Digital nomad. Wiley, Chichester

27. Siau K, Shen Z (2003) Mobile communications and mobile services. Int J Mob Commun 1 (1):3-14

28. Elliott G, Phillips N (2004) Mobile Commerce and Wireless Computing Systems. Pearson Education, Harlow

29. Nikita B, Ian G, David W (2001) Intercepting Mobile Communications: The Insecurity of 802.11.

30. Ravi S, Raghunathan A, Potlapally N (2002) Securing wireless data: system architecture challenges. Paper presented at the Proceedings of the 15th international symposium on System Synthesis, Kyoto, Japan,

31. Orr JE (1996) Talking about machines : an ethnography of a modern job. ILR Press, Ithaca

32. Andersson B Harnessing handheld computing - Managing IS support to the digital ranger with defensive design. In: Proceedings of the Sixth International Conference on Design Science Research in Information Systems and Technology (DESRIST 2011), Milwaukee, 2011.

33. Andersson B, Carlsson SA (2009) Designing for Digital Nomads: Managing the High Reliance on Single Application. Paper presented at the Proceedings of the Global Mobility Roundtable, Cairo,

34. Gregor S (2006) The Nature of Theory in Information Systems. MIS Quarterly 3:611-642 